DOI: $10.31294 /$ jtk.v4i2

\title{
Rancang Bangun Sistem Informasi Pemesanan Jasa Event Organizer Berbasis Website Menggunakan Metode RAD \\ Khairul Rizal $^{1}$, Yuris Alkhalifi ${ }^{2}$, Firstianty Wahyuhening Fibriany ${ }^{3}$, Zahrah Rachmawaty ${ }^{4}$ \\ 1,2,3,4 Fakultas Teknik dan Informatika, Universitas Bina Sarana Informatika \\ 1e-mail: khairul.krl@bsi.ac.id \\ 2e-mail: yuris.yak@bsi.ac.id \\ 3e-mail: firstianty.fbr@bsi.ac.id \\ ${ }^{4}$ e-mail: zahrah12183100@bsi.ac.id
}

\begin{abstract}
Abstrak - Teknologi membuat segala bentuk aktivitas manusia menjadi lebih praktis dan mudah. Para pengusaha pun sudah banyak yang memanfaatkan teknologi untuk mengembangkan usahanya, baik memasarkan maupun memberikan informasi mengenai perusahaannya secara online termasuk pada PT. Tekno Pasifik Indonesia. PT. Tekno Pasifik Indonesia merupakan perusahaan yang bergerak di bidang jasa event organizer. Pada saat ini, PT. Tekno Pasifik Indonesia masih menggunakan sistem manual, baik dalam promosi jasa, pemesanan, bahkan transaksi yang dilakukan, sehingga tidak menutup kemungkinan akan terjadinya suatu kesalahan saat proses berlangsung dalam pencatatan pemesanan, transaksi, bahkan waktu pelaksanaan event yang bertabrakan. Untuk itu, perlu dibuatnya sebuah sistem rancang bangun pemesanan jasa event organizer untuk menunjang dan memberikan pelayanan yang dapat memuaskan para pelanggan berbasis website. Rancang bangun website pada penelitian ini menggunakan metode Rapid Application Development (RAD) dengan menggunakan diagram Unified Modelling Language (UML) berupa Usecase \& Activity Diagram, kemudian pemodelan basis data menggunakan Entity Relationship Diagram (ERD) dan Logical Record Structure (LRS). Hasil akhir implementasi akhir pada program yang dicapai diharapkan dapat tercapainya suatu kegiatan yang efektif dan efisien dalam menunjang pelayanan pada pelanggan.
\end{abstract}

Kata Kunci: Rancang Bangun Website, Event Organizer, RAD

\begin{abstract}
Technology makes all forms of human activity more practical and easier. Many entrepreneurs have also used technology to develop their businesses, both marketing and providing information about their companies online, including at PT. Indonesian Pacific Techno. PT. Tekno Pasifik Indonesia is a company engaged in event organizer services. At this time, PT. Tekno Pasifik Indonesia still uses a manual system, both in service promotions, orders, and even transactions, so it is possible for an error to occur during the process of recording orders, transactions, and even the timing of colliding events. For this reason, it is necessary to create a design and build system for ordering event organizer services to support and provide services that can satisfy website-based customers. Website design in this study uses the Rapid Application Development (RAD) method using Unified Modeling Language (UML) diagrams in the form of Usecase \& Activity Diagrams, then database modeling using Entity Relationship Diagram (ERD) and Logical Record Structure (LRS). The final result of the final implementation of the program is expected to be able to achieve an activity that is effective and efficient in supporting customer service.
\end{abstract}

Keywords: Website Design, Event Organizer, RAD

\section{PENDAHULUAN}

Event Organizer (EO) adalah suatu organisasi penyedia jasa professional yang didalamnya terdapat beberapa tim yang memiliki tugas masing - masing tiap anggotanya untuk mencapai suatu tujuan dalam suatu acara tertentu (Juniansyah et. al, 2020). Maka dari itu setiap perusahaan penyedia jasa EO berlomba-lomba meningkatkan kreativitas mereka dan kemampuan mereka demi bisa bersaing dengan 
perusahaan-perusahaan yang sejenis untuk mendapatkan customer.

Sejak awal berdiri PT. Tekno Pasifik Indonesia masih belum banyak dikenal oleh masyarakat luas, sehingga customer yang menggunakan jasa perusahaan tersebut masih sedikit. Para staff di bagian marketing harus mendatangi setiap instansi pemerintahan atau perusahaan untuk mempromosikan perusahaannya guna mendapatkan customer. Masalah yang tengah dihadapi oleh PT. Tekno Pasifik Indonesia adalah terbatasnya customer yang hanya mendapatkan promosi dari staff marketing saja dan apabila ingin menyewa atau memesan jasa event harus datang langsung ke PT. Tekno Pasifik Indonesia sampai pada tahap pembayaran atau transaksi yang dilakukan secara langsung.

Saat ini teknologi sudah berkembang dengan sangat pesat, salah satunya adalah teknologi internet khususnya dalam dunia bisnis, hal ini dapat dilihat dengan hadirnya perdagangan elektronik atau $e$ commerce(Farlina et al. 2019). E-commerce adalah penjualan, pembelian dan pemasaran barang atau jasa melalui sistem elektronik. Seperti radio, televisi dan jaringan komputer atau Internet. Dengan adanya teknologi e-commerce dapat memudahkan pelanggan untuk mencari informasi tentang produk atau jasa yang ditawarkan di halaman website dan memudahkan pelanggan untuk memesan produk atau jasa dari EO hingga transaksi(Septiani et al. 2019). Website dapat menyediakan informasi dan dapat diakses oleh semua masyakarat secara langkap dan mudah(Puspita, et, al. 2021).

Sistem e-commerce memudahkan transmisi informasi produk/jasa dan pemesanan produk atau jasa untuk event yang akan dipesan oleh pelanggan. Dengan menggunakan teknologi e-commerce untuk memesan produk/layanan, pelanggan akan menerima layanan 24 jam untuk mempertahankan pelanggan yang sudah ada dan menarik perhatian pelanggan baru atau lama(Juniansyah et al. 2020).

Penelitian sebelumnya dilakukan pembuatan analisis dan perancangan sistem informasi Event Organizer berbasis Website pada Antique Salon dan Pelaminan menggunakan metode Waterfall dan menggunakan diagram Unified Modeling Language(UML) dan dibangun menggunakan Framework CodeIgniter 4, Library Bootstrap 4 dan database MySQL. Hasil akhir pada penelitian ini adalah dibuatnya analisis perancangan website menyampaikan informasi detail mengenai detail barang, paket, layanan yang ditawarkan dan fitur lainnya(Pratama and Syastra 2021).

Penelitian lainnya dilakukan pembuatan perancangan elektronik marketplace EO menggunakan metode
Scrum. Penelitian ini menghasilkan sebuah website dan dengan tujuan untuk memberikan solusi bagi pengguna untuk meminta layanan EO dan dapat berkontribusi pada pembahasan perancangan perangkat lunak, terutama e-marketplace, sebagai sarana untuk mempromosikan dan media transaksi EO(Setiawan 2019).

Adapun pada penelitian ini akan dibuat sebuah sebuah rancang bangun sistem informasi pemesanan pada PT. Tekno Pasifik Indonesia menggunakan metode RAD. Penelitian ini bertujuan untuk mempermudah perusahaan maupun pelanggan dalam menawarkan dan menerima informasi mengenai produk atau jasa, melakukan pemesanan dan tranasaksi, memperluas pemasaran bahkan memudahkan perusahaan dalam merekap penjadwalan dan laporan pemesanan.

\section{METODOLOGI PENELITIAN}

\section{Teknik Pengambilan Data}

Dalam teknik pengambilan data, tedapat 2 macam yakni Teknik pengambilan data primer dan sekunder. Data primer adalah data yang diperoleh dari wawancara, observasi, angket dan metode lainnya (Alkhalifi et al. 2020). Sedangkan data sekunder merupakan data yang diperoleh dari obyek penelitian lain berupa dokumentasi yang berasal dari sumber data lain(Alkhalifi et al. 2020). Pada penelitian ini dilakukan teknik pengambilan data primer yakni menggunakan metode observasi wawancara dan studi pustaka.

\section{a. Observasi}

Observasi (pengamatan) dilakukan secara langsung terhadap kegiatan yang berkaitan dengan masalah yang diambil. Hasil dari pengamatan tersebut kemudian dicatatan. Pada metode ini, diamati secara langsung permasalahan yang terjadi pada perusahaan mengenai pemesanan hingga pada transaksi pemesanan jasa event organizer.

\section{b. Wawancara}

Dilakukan tanya jawab secara langsung dan sistematis kepada bapak Mahbub, SE selaku Manager HRD dan GA pada PT. Tekno Pasifik Indonesia mengenai sistem informasi yang berjalan di perusahaan baik cara pemesanan maupun promosi mengenai jasa event yang ditawarkan perusahaan tersebut.

\section{c. Studi Pustaka}

Dilakukan pencarian referensi baik dari jurnal, buku dan semua referensi yang berkaitan dengan penelitian ini, serta berkas dokumen yang diperoleh dari data internal PT. Tekno Pasifik Indonesia.

\section{Metode Pengembangan Sistem}

Pada setiap pengembangan sistem diperlukan sebuah System Development Life Cycle (SDLC). SDLC merupakan proses mengembangkan atau memodifikasi sistem perangkat lunak menggunakan 
model dan metodologi yang digunakan untuk mengembangkan sistem perangkat lunak sebelumnya(Hakim et al. 2019).

Metode SDLC yang dipakai pada penelitian ini adalah metode Rapid Application Development (RAD). Metode RAD adalah salah satu metode yang sering digunakan pada pengembangan SDLC(Sofyan et al. 2016). Metode RAD merupakan adalah model proses pengembangan perangkat lunak dengan waktu pengerjaaan yang pendek(Rudianto et al. 2021). Metode RAD merupakan adaptasi dari model air terjun (waterfall) dengan menggunakan model air terjun untuk pengembangan setiap komponen perangkat lunak namun dengan versi kecepatan tinggi(Sukamto \& Shalahuddin 2018). Metode ini membagi tim pengembangan menjadi beberapa tim dan bekerja pada beberapa komponen. Setiap kelompok kerja dapat bekerja secara paralel.

Dalam pengembangan sistem pada metode RAD terdiri dari 5 tahapan yakni Pemodelan Bisnis, Pemodelan Data, Pemodelan Proses, Pembuatan Aplikasi dan Pengujian \& Pergantian. Adapun gambar dari tahapan tersebut dapat dilihat pada

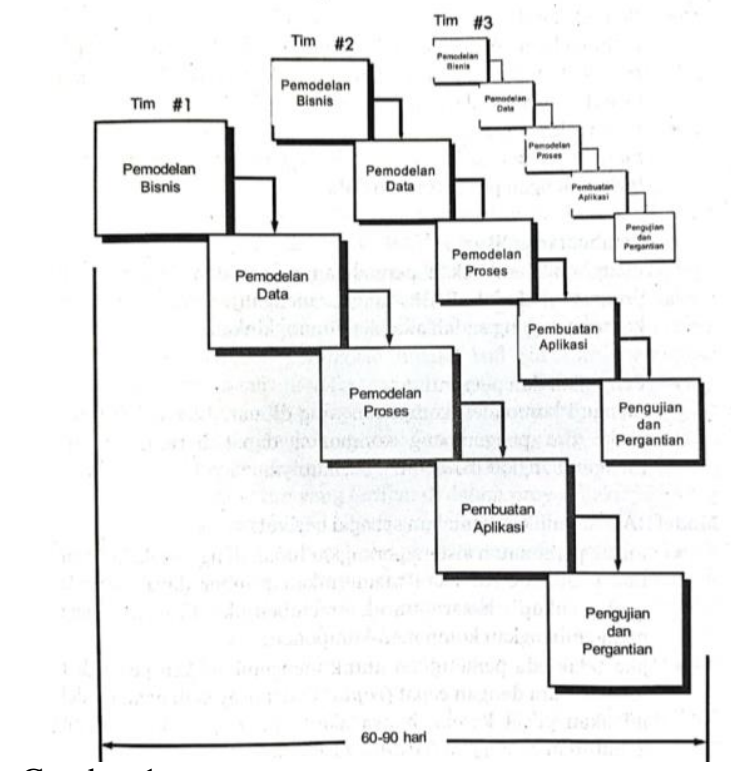

Gambar 1.

Sumber : (Sukamto \& Shalahuddin 2018)

Gambar 1. Tahapan Metode RAD

a. Pemodelan Bisnis

Model fungsi bisnis, informasi apa yang terlibat dalam proses bisnis, informasi apa yang perlu dihasilkan, siapa yang membuat informasi, bagaimana informasi mengalir, apa prosesnya. Hal ini dilakukan untuk mengetahui apakah ada kaitannya dengan informasi tersebut atau tidak(Sukamto \& Shalahuddin 2018).

Pada tahap ini dilakukan pengumpulkan dokumentasi dan membahas kebutuhan sistem, Kemudian menganalisis informasi ini dan menggunakannya untuk menentukan spesifikasi file.

\section{b. Pemodelan Data}

Memodelkan data yang dibutuhkan berdasarkan pemodelan bisnis dan mendefinisikan atributatributnya beserta relasinya dengan data-data yang lain(Sukamto \& Shalahuddin 2018).

Pada tahap ini dirancang sebuah pemodelan basis data untuk mempermudah pemodelan data yakni ERD, LRS \& Class Diagram sehingga dapat diketahui atribut apa saja yang akan digunakan dan diperlukan serta bagaimana relasinya.

c. Pemodelan Proses

Mengimplementasikan fungsi bisnis yang sudah didefinisikan terkait dengan pendefinisian data(Sukamto \& Shalahuddin 2018).

Pada tahap ini dibuat sebuah pemodelan proses dengan menggunakan usecase sebagai identifikasi proses bisnis dan activity diagram sebagai pemodelan proses bisnis

\section{d. Pembuatan Aplikasi}

Mengimplementasikan pemodelan data dan pemodelan bisnis menjadi sebuah program(Sukamto \& Shalahuddin 2018).

Pada tahap ini dibangun sebuah program dengan menggunakan HTML, bahasa pemrograman PHP dan CSS dari desain yang dibuat sebelumnya.

\section{e. Pengujian dan Pergantian}

Menguji semua komponen yang sudah dibuat agar tim pengembang komponen dapat melanjutkan proses untuk mengembangkan komponen berikutnya.

Pada tahap ini dilakukan pengujian blackbox testing untuk mengetahui apakah program sudah berjalan sesuai dengan prosedur yang diinginkan atau belum.

\section{HASIL DAN PEMBAHASAN}

1. Pemodelan Bisnis

Berikut ini analisa skenario kebutuhan dari sistem informasi yang dibutuhkan.

A. Skenario kebutuhan Administrator

A1. Administrator mengelola data Administrator.

A2. Administrator mengelola data paket.

A3. Administrator mengelola data pemesanan.

A4. Administrator mengelola data pembayaran.

A5. Administrator mengelola data tentang kami.

A6. Administrator mengelola data kontak kami.

B. Skenario Kebutuhan Pelanggan Terdaftar

B1. Pelanggan melakukan registrasi akun.

B2. Pelanggan melakukan pemesanan.

B3. Pelanggan mengelola informasi akun.

B4. Pelanggan berinteraksi dengan Administrator melalui forum live chatt.

B5. Pelanggan melakukan pembayaran kepada EO PT. Tekno Pasifik Indonesia.

B6. Pelanggan mengupload bukti pembayaran.

B7. Pelanggan memberikan kritik dan saran atas pelayanan dari PT. Tekno Pasifik Indonesia.

C. Skenario Kebutuhan Pengujung

C1. Pengunjung dapat melihat halaman informasi seputar PT. Tekno Pasifik Indonesia dan 
mengunduh file company profile.

C2. Pengunjung dapat melihat paket apa saja yang ditawarkan.

C3. Pengunjung dapat melihat galeri foto yang berisi kegiatan event yang telah dilaksanakan menggunakan jasa event organizer PT. Tekno Pasifik Indonesia.

C4. Pengunjung dapat melihat kontak perusahaan yang dapat dihubungi.

C5. Pengunjung dapat melihat cara pemesanan jasa event organizer secara online.

C6. Pengunjung dapat melihat kritik dan saran apa saja yang telah diberikan oleh pelanggan yang menggunakan jasa PT. Tekno Pasifik Indonesia.

C7. Pengunjung dapat melakukan registrasi akun atau login.

2. Pemodelan Data

Berikut ini adalah pemodelan basis data antara lain ERD, LRS dan spesifikasi file yang sudah dimodelkan.

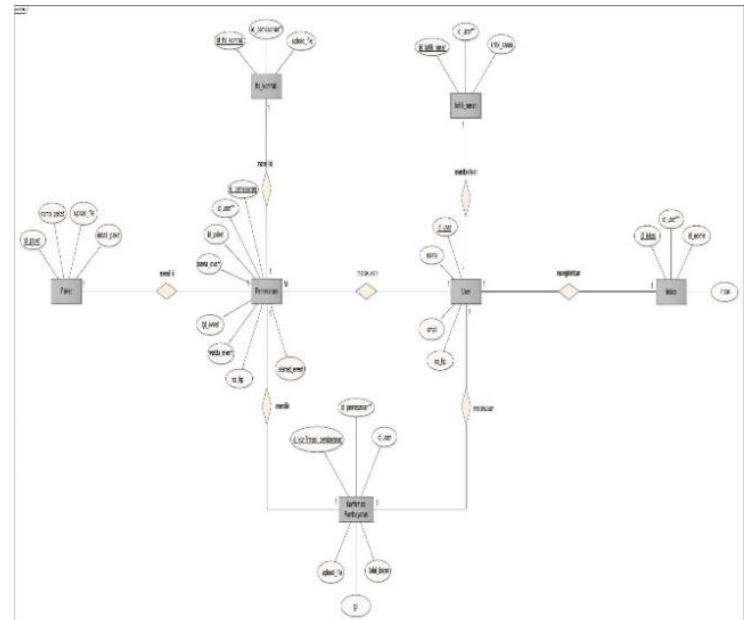

Sumber : Penelitian (2021)

Gambar 2. Entity Relationship Diagram

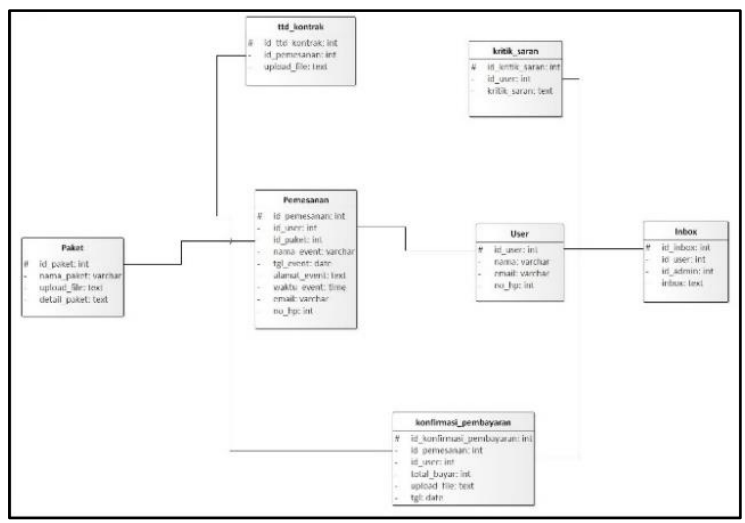

Sumber : Penelitian (2021)

Gambar 3. Logical Record Structures

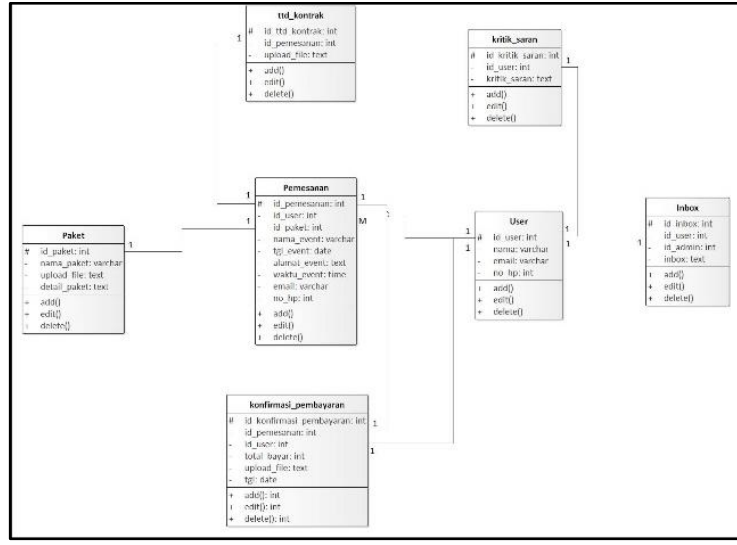

Sumber : Penelitian (2021)

Gambar 4. Class Diagram

3. Pemodelan Proses

Berikut ini adalah pemodelan usecase dan activity diagram yang sudah dibuat.

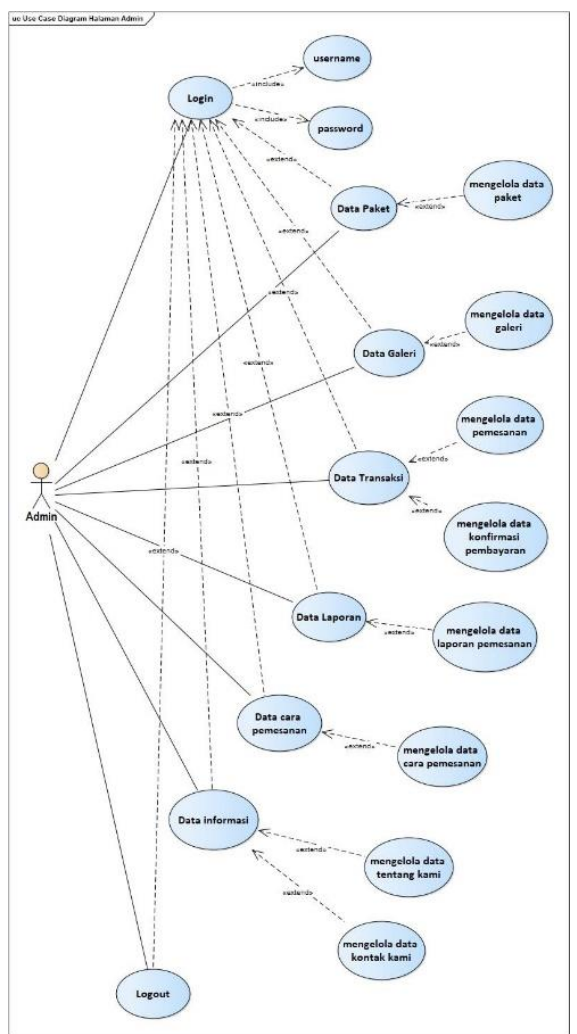

A. Halaman Administrator

Sumber : Penelitian (2021)

Gambar 5. Usecase Diagram Administratoristrator

Tabel 1. Deskripsi UseCase Login Administratoristrator

\begin{tabular}{lll}
\hline $\begin{array}{l}\text { UseCase } \\
\text { Name }\end{array}$ & Akses Administratoristrator \\
\hline Requirements & $\begin{array}{l}\text { Administratoristrator } \\
\text { login. }\end{array}$ & Akses \\
\hline Goal & $\begin{array}{l}\text { Administratoristrator dapat Akses } \\
\text { halaman Administrator. }\end{array}$ & \\
\hline
\end{tabular}




\begin{tabular}{lll}
\hline $\begin{array}{l}\text { Pre- } \\
\text { Conditions }\end{array}$ & $\begin{array}{l}\text { Administratoristrator } \\
\text { email dan password. }\end{array}$ & Akses \\
\hline $\begin{array}{l}\text { Post- } \\
\text { Conditions }\end{array}$ & $\begin{array}{l}\text { Administratoristrator } \\
\text { akses login. }\end{array}$ & sukses \\
\hline $\begin{array}{l}\text { Failed end } \\
\text { Condition }\end{array}$ & $\begin{array}{l}\text { Administratoristrator } \\
\text { berhasil akses login. }\end{array}$ & tidak \\
\hline Actors & Administratoristrator & \\
\hline Main Flow / & 1. & $\begin{array}{l}\text { Administratoristrator } \\
\text { menginput email. } \\
\text { Basic Path }\end{array}$ \\
& 2. & $\begin{array}{l}\text { Administratoristrator } \\
\text { menginput password. }\end{array}$ \\
& 3. $\begin{array}{l}\text { Sistem menampilkan } \\
\text { halaman utama } \\
\text { Administratoristrator. }\end{array}$ \\
\hline
\end{tabular}

Tabel 2. Deskripsi UseCase Data Paket

\begin{tabular}{llc}
\hline $\begin{array}{l}\text { UseCase } \\
\text { Name }\end{array}$ & Data paket & \\
\hline Requirements & $\begin{array}{l}\text { Administratoristrator } \\
\text { mengelola data paket. }\end{array}$ & bisa \\
\hline Goal & $\begin{array}{l}\text { Administratoristrator bisa } \\
\text { mengakses halaman data paket. }\end{array}$ \\
\hline $\begin{array}{l}\text { Pre- } \\
\text { Conditions }\end{array}$ & $\begin{array}{l}\text { Administratoristrator melakukan } \\
\text { login. }\end{array}$ \\
\hline $\begin{array}{l}\text { Post- } \\
\text { Conditions }\end{array}$ & $\begin{array}{l}\text { Administratoristrator } \\
\text { merubah data paket. }\end{array}$ \\
\hline $\begin{array}{l}\text { Failed end } \\
\text { Condition }\end{array}$ & $\begin{array}{l}\text { Administratoristrator } \\
\text { berhasil merubah data paket. }\end{array}$ \\
\hline Actors & Administratoristrator \\
\hline $\begin{array}{l}\text { Main Flow / } \\
\text { Basic Path }\end{array}$ & $\begin{array}{l}\text { Administratoristrator akses } \\
\text { pilihan menu data paket. } \\
\text { Tampil halaman data paket } \\
\text { pada sistem }\end{array}$ \\
\hline Sumber : Penelitian (2021)
\end{tabular}

Tabel 3 Deskripsi UseCase Data Galeri

\begin{tabular}{|c|c|}
\hline $\begin{array}{l}\text { UseCase } \\
\text { Name }\end{array}$ & Data galeri \\
\hline Requirements & $\begin{array}{l}\text { Administratoristrator bisa kelola } \\
\text { data galeri. }\end{array}$ \\
\hline Goal & $\begin{array}{l}\text { Administratoristrator } \\
\text { mengakses data galeri. }\end{array}$ \\
\hline $\begin{array}{l}\text { Pre- } \\
\text { Conditions }\end{array}$ & $\begin{array}{l}\text { Administratoristrator melakukan } \\
\text { login. }\end{array}$ \\
\hline $\begin{array}{l}\text { Post- } \\
\text { Conditions }\end{array}$ & $\begin{array}{l}\text { Administratoristrator } \\
\text { merubah data galeri. }\end{array}$ \\
\hline $\begin{array}{l}\text { Failed end } \\
\text { Condition }\end{array}$ & $\begin{array}{l}\text { Administratoristrator } \\
\text { berhasil merubah data galeri. }\end{array}$ \\
\hline Actors & Administrator \\
\hline $\begin{array}{l}\text { Main Flow / } \\
\text { Basic Path }\end{array}$ & $\begin{array}{l}\text { 1. Administrator akses pilihan } \\
\text { menu data galeri. } \\
\text { 2. Tampil halaman data galeri, } \\
\text { pada sistem }\end{array}$ \\
\hline
\end{tabular}

Sumber : Penelitian (2021)

Tabel 4. Deskripsi UseCase Data Transaksi

UseCase Data transaksi

\begin{tabular}{|c|c|}
\hline Name & \\
\hline Requirements & $\begin{array}{l}\text { Administrator bisa kelola data } \\
\text { transaksi. }\end{array}$ \\
\hline Goal & $\begin{array}{l}\text { Administrator bisa mengakses } \\
\text { halaman data transkaksi. }\end{array}$ \\
\hline $\begin{array}{l}\text { Pre- } \\
\text { Conditions }\end{array}$ & Administrator melakukan login. \\
\hline $\begin{array}{l}\text { Post- } \\
\text { Conditions }\end{array}$ & $\begin{array}{l}\text { Administrator berhasil merubah } \\
\text { data transaksi. }\end{array}$ \\
\hline $\begin{array}{l}\text { Failed end } \\
\text { Condition }\end{array}$ & $\begin{array}{l}\text { Administrator tidak berhasil } \\
\text { merubah data transaksi. }\end{array}$ \\
\hline Actors & Administrator \\
\hline $\begin{array}{l}\text { Main Flow / } \\
\text { Basic Path }\end{array}$ & $\begin{array}{l}\text { 1. Administrator akses pilihan } \\
\text { menu data transaksi. } \\
\text { 2. Tampil halaman data transaksi, } \\
\text { pada sistem }\end{array}$ \\
\hline
\end{tabular}

Sumber : Penelitian (2021)

Tabel 5. Deskripsi UseCase Data Laporan

\begin{tabular}{ll}
\hline $\begin{array}{l}\text { UseCase } \\
\text { Name }\end{array}$ & Data laporan \\
\hline Requirements & $\begin{array}{l}\text { Administrator bisa mengelola } \\
\text { halaman data laporan. }\end{array}$ \\
\hline Goal & $\begin{array}{l}\text { Administrator dapat mengakses } \\
\text { halaman data laporan. }\end{array}$ \\
\hline $\begin{array}{l}\text { Pre- } \\
\text { Conditions }\end{array}$ & Administrator melakukan login. \\
\hline $\begin{array}{l}\text { Post- } \\
\text { Conditions }\end{array}$ & $\begin{array}{l}\text { Administrator berhasil merubah } \\
\text { data laporan. }\end{array}$ \\
\hline $\begin{array}{l}\text { Failed end } \\
\text { Condition }\end{array}$ & $\begin{array}{l}\text { Administrator tidak berhasil } \\
\text { merubah data laporan. }\end{array}$ \\
\hline Actors & Administrator \\
\hline $\begin{array}{l}\text { Main Flow / } \\
\text { Basic Path }\end{array}$ & $\begin{array}{l}\text { Administrator akses } \\
\text { pilihan menu data laporan. } \\
\text { Tampil halaman data } \\
\text { laporan, pada sistem }\end{array}$ \\
\hline
\end{tabular}

Sumber : Penelitian (2021)

Tabel 6. Deskripsi UseCase Data Cara Pemesanan UseCase Data cara pemesanan

Name

Requirements Administrator bisa kelola halaman data cara pemesanan.

Goal Administrator bisa mengakses

halaman data pemesanan.

Pre- Administrator melakukan login.

Conditions

Post- Administrator berhasil merubah

Conditions data cara pemesanan.

Failed end Administrator tidak berhasil

Condition merubah data cara pemesanan.

\begin{tabular}{lcl}
\hline Actors & Administrator \\
\hline Main Flow / & 1. & $\begin{array}{l}\text { Administrator akses } \\
\text { pilihan menu data cara } \\
\text { Basic Path }\end{array}$ \\
& 2. $\begin{array}{l}\text { Temesanan. } \\
\text { Tampil halaman data cara } \\
\text { pemesanan, pada sistem }\end{array}$ \\
\hline
\end{tabular}

Sumber : Penelitian (2021) 


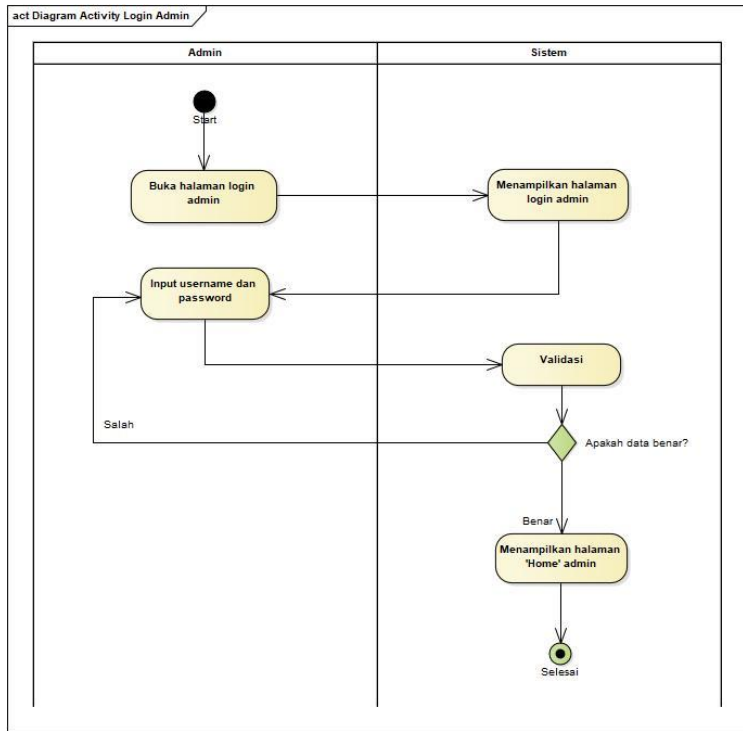

Sumber : Penelitian (2021)

Gambar 6. Activity Diagram Login Administrator

B. Halaman Pelanggan Terdaftar

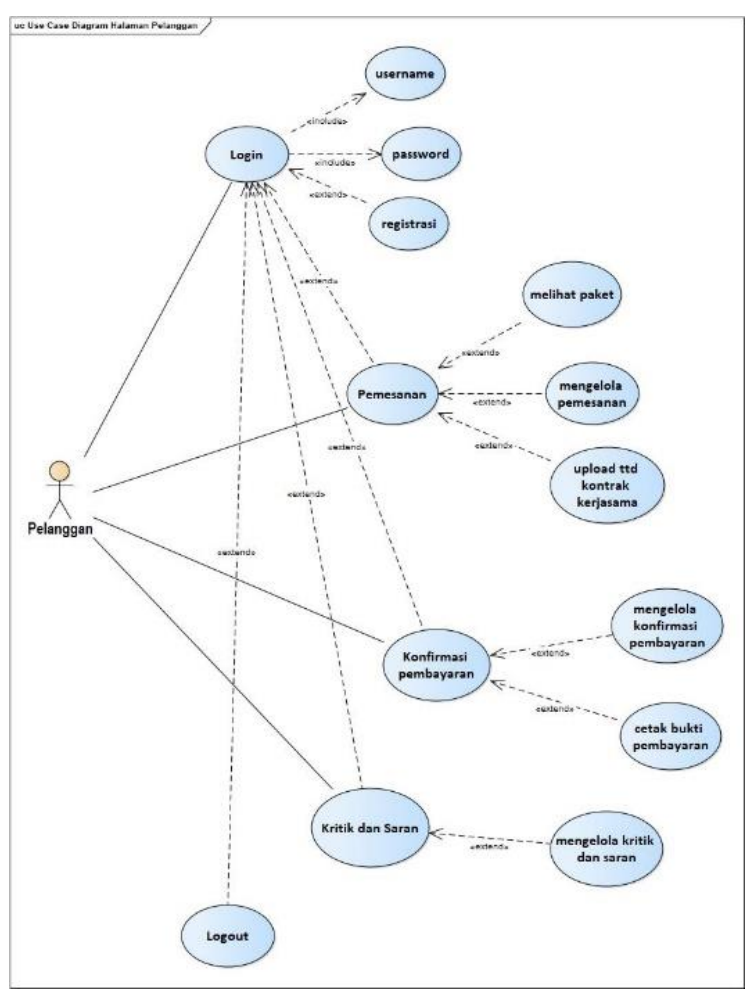

Sumber : Penelitian (2021)

Gambar 7. Usecase Diagram Pelanggan Terdaftar

Tabel 7. Deskripsi UseCase Login

\begin{tabular}{ll}
\hline UseCase Login \\
Name
\end{tabular}

\begin{tabular}{ll}
\hline Requirements & Pelanggan bisa melakukan login. \\
\hline Goal & $\begin{array}{l}\text { Pelanggan bisa mengakses menu } \\
\text { pemesanan. }\end{array}$ \\
\hline $\begin{array}{l}\text { Pre- } \\
\text { Conditions }\end{array}$ & $\begin{array}{l}\text { Pelanggan menginput email dan } \\
\text { password. }\end{array}$ \\
\hline $\begin{array}{l}\text { Post- } \\
\text { Conditions }\end{array}$ & Pelanggan sukses login. \\
\hline $\begin{array}{l}\text { Failed end } \\
\text { Condition }\end{array}$ & Pelanggan tidak berhasil login. \\
\hline Actors & Pelanggan \\
\hline $\begin{array}{l}\text { Main Flow / } \\
\text { Basic Path }\end{array}$ & 2. Pelanggan input email. \\
\hline Sumber : Penelitian (2021)
\end{tabular}

Tabel 8. Deskripsi UseCase Registrasi

\begin{tabular}{|c|c|}
\hline $\begin{array}{l}\text { UseCase } \\
\text { Name }\end{array}$ & Registrasi \\
\hline Requirements & Pelanggan bisa login. \\
\hline Goal & $\begin{array}{l}\text { Pelanggan bisa melakukan } \\
\text { pemesanan. }\end{array}$ \\
\hline $\begin{array}{l}\text { Pre- } \\
\text { Conditions }\end{array}$ & $\begin{array}{l}\text { Pelanggan melakuan pengisian } \\
\text { data registrasi }\end{array}$ \\
\hline $\begin{array}{l}\text { Post- } \\
\text { Conditions }\end{array}$ & $\begin{array}{l}\text { Pelanggan dapat melakukan } \\
\text { pemesanan. }\end{array}$ \\
\hline $\begin{array}{l}\text { Failed end } \\
\text { Condition }\end{array}$ & $\begin{array}{l}\text { Pelanggan tidak jadi melakukan } \\
\text { registrasi. }\end{array}$ \\
\hline Actor & Pelanggan \\
\hline $\begin{array}{l}\text { Main Flow / } \\
\text { Black Path }\end{array}$ & $\begin{array}{l}\text { 1. Pelanggan terlebih dahulu } \\
\text { melakukan registrasi. } \\
\text { 2. Pelanggan berhasil } \\
\text { melakukan registrasi. } \\
\text { 3. Pelanggan mengisi data } \\
\text { registrasi. } \\
\text { 4. Pelanggan dapat } \\
\text { melakukan pemesanan. }\end{array}$ \\
\hline
\end{tabular}

Sumber : Penelitian (2021)

Tabel 9. Deskripsi UseCase Pemesanan

\begin{tabular}{|c|c|}
\hline $\begin{array}{l}\text { UseCase } \\
\text { Name }\end{array}$ & Pemesanan \\
\hline Requirements & $\begin{array}{l}\text { Pelanggan bisa memilih paket } \\
\text { seperti diinginkan. }\end{array}$ \\
\hline Goal & $\begin{array}{l}\text { Pelanggan bisa melakukan } \\
\text { pemesanan }\end{array}$ \\
\hline $\begin{array}{l}\text { Pre- } \\
\text { Conditions }\end{array}$ & Pelanggan berhasil login. \\
\hline $\begin{array}{l}\text { Post- } \\
\text { Conditions }\end{array}$ & $\begin{array}{l}\text { Pelanggan dapat mengakses } \\
\text { menu pemesanan. }\end{array}$ \\
\hline $\begin{array}{l}\text { ailed end } \\
\text { Condition }\end{array}$ & $\begin{array}{l}\text { Pelanggan tidak jadi melakukan } \\
\text { pemesanan }\end{array}$ \\
\hline Actor & Pelanggan \\
\hline $\begin{array}{l}\text { Main Flow / } \\
\text { Black Path }\end{array}$ & $\begin{array}{l}\text { 1. Pelanggan akses pilihan } \\
\text { menu pemesanan. } \\
\text { 2. Tampil halaman pemesanan. }\end{array}$ \\
\hline
\end{tabular}

Sumber : Penelitian (2021) 
Tabel 10. Deksripsi UseCase Konfirmasi Pembayaran

\begin{tabular}{|c|c|}
\hline $\begin{array}{l}\text { UseCase } \\
\text { Name }\end{array}$ & Validasi Pembayaran \\
\hline Requirements & $\begin{array}{l}\text { Pelanggan bisa lakukan validasi } \\
\text { pembayaran. }\end{array}$ \\
\hline Goal & $\begin{array}{l}\text { Pelanggan bisa mengelola } \\
\text { validasi pembayaran. }\end{array}$ \\
\hline $\begin{array}{l}\text { Pre- } \\
\text { Conditions }\end{array}$ & Pelanggan sukses login. \\
\hline $\begin{array}{l}\text { Post- } \\
\text { Conditions }\end{array}$ & $\begin{array}{l}\text { Pelanggan sukses kelola validasi } \\
\text { pembayaran. }\end{array}$ \\
\hline $\begin{array}{l}\text { Failed end } \\
\text { Condition }\end{array}$ & $\begin{array}{ll}\text { Pelanggan } & \text { membatalkan } \\
\text { pembayaran. } & \end{array}$ \\
\hline Actor & Pelanggan \\
\hline $\begin{array}{l}\text { Main Flow / } \\
\text { Black Path }\end{array}$ & $\begin{array}{l}\text { 1. Pelanggan akses pilihan } \\
\text { menu konfirmasi } \\
\text { pembayaran. } \\
\text { 2. Tampil halaman validasi } \\
\text { pembayaran. }\end{array}$ \\
\hline $\begin{array}{l}\text { Sumber: Penelit } \\
\text { Tabel 11. De } \\
\end{array}$ & skripsi UseCase Kritik dan Saran \\
\hline $\begin{array}{l}\text { UseCase } \\
\text { Name }\end{array}$ & Kritik dan Saran \\
\hline Requirements & $\begin{array}{l}\text { Pelanggan bisa menuliskan kritik } \\
\text { dan saran }\end{array}$ \\
\hline Goal & $\begin{array}{l}\text { Pelanggan dapat mengelola } \\
\text { kritik dan saran }\end{array}$ \\
\hline $\begin{array}{l}\text { Pre- } \\
\text { Conditions }\end{array}$ & Pelanggan sukses login. \\
\hline $\begin{array}{l}\text { Post- } \\
\text { Conditions }\end{array}$ & $\begin{array}{l}\text { Pelanggan berhasil kelola kritik } \\
\text { dan saran }\end{array}$ \\
\hline $\begin{array}{l}\text { Failed end } \\
\text { Condition }\end{array}$ & $\begin{array}{l}\text { Pelanggan membatalkan } \\
\text { menuliskan kritik dan saran }\end{array}$ \\
\hline Actor & Pelanggan \\
\hline $\begin{array}{l}\text { Main Flow / } \\
\text { Black Path }\end{array}$ & $\begin{array}{l}\text { 1. Pelanggan akses pilihan } \\
\text { menu kritik dan saran. } \\
\text { 2. Tampil halaman kritik dan } \\
\text { saran. }\end{array}$ \\
\hline
\end{tabular}

Sumber : Penelitian (2021)

4. Pembuatan Aplikasi

Setelah dilakukan perancangan, berikutnya adalah pembuatan aplikasi. Adapun tampilan aplikasi dapat dilihat seperti berikut ini.

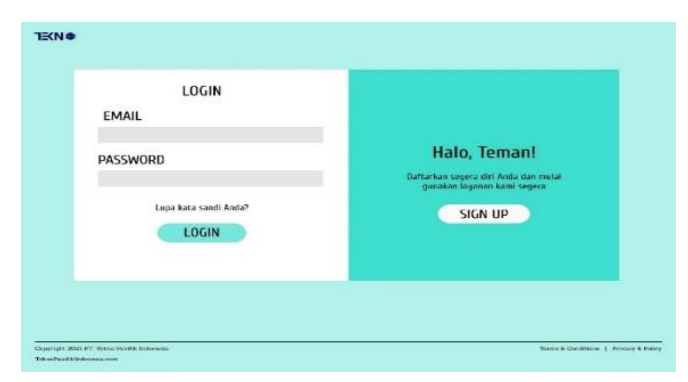

Sumber : Penelitian (2021)

Gambar 9. Tampilan Form Login Pelanggan

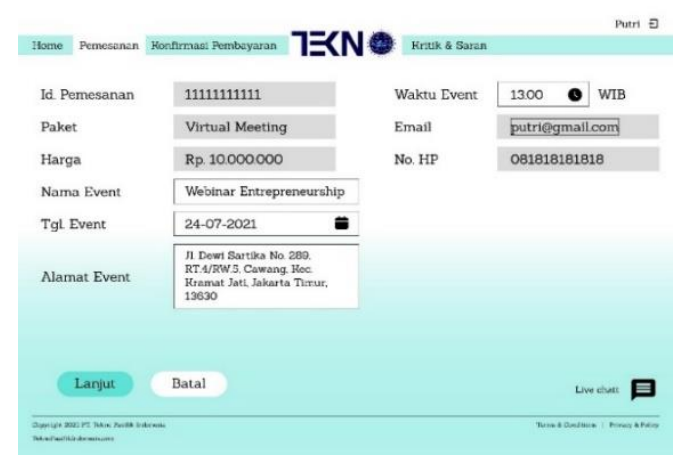

Sumber : Penelitian (2021)

Gambar 11. Tampilan Form Pemesanan

5. Pengujian dan Pergantian

Dalam pengujian ini akan dibagi kedalam 2 bagian yakni pengujian pada front-end dan pengujian pada back-end. Tabel pengujian dapat dilihat seperti berikut ini.

A. Pengujian Front-End

\begin{tabular}{|c|c|c|c|c|c|c|c|}
\hline $\begin{array}{c}\text { Partisipa } \\
\text { n }\end{array}$ & $\begin{array}{l}\text { Akses } \\
\text { Menu }\end{array}$ & $\begin{array}{c}\begin{array}{c}\text { Registra } \\
\text { si } \\
\text { Pelangg } \\
\text { an }\end{array} \\
\end{array}$ & $\begin{array}{c}\text { Akses } \\
\text { Pemesan } \\
\text { an }\end{array}$ & $\begin{array}{c}\text { Login } \\
\text { Membe } \\
\mathrm{r}\end{array}$ & $\begin{array}{c}\text { Akses } \\
\text { Transak } \\
\text { si }\end{array}$ & $\begin{array}{c}\text { Akses } \\
\text { Kritik } \\
\& \\
\text { Saran } \\
\end{array}$ & $\begin{array}{l}\text { Akses } \\
\text { Inbox }\end{array}$ \\
\hline 1 & $\checkmark$ & $\checkmark$ & $\checkmark$ & $\checkmark$ & $\checkmark$ & $\checkmark$ & $\checkmark$ \\
\hline 2 & $\checkmark$ & $\checkmark$ & $\checkmark$ & $\checkmark$ & $\checkmark$ & $\checkmark$ & $\checkmark$ \\
\hline 3 & $\checkmark$ & $\checkmark$ & $\checkmark$ & $\checkmark$ & $\checkmark$ & $\checkmark$ & $\checkmark$ \\
\hline 4 & $\checkmark$ & $\checkmark$ & $\checkmark$ & $\checkmark$ & $\checkmark$ & $\checkmark$ & $\checkmark$ \\
\hline 5 & $\checkmark$ & $\checkmark$ & $\checkmark$ & $\checkmark$ & $\checkmark$ & $\checkmark$ & $\checkmark$ \\
\hline $\begin{array}{c}\text { Sukse } \\
\text { s }\end{array}$ & 5 & 5 & 5 & 5 & 5 & 5 & 5 \\
\hline $\begin{array}{c}\text { Nilai } \\
\text { Kesukses } \\
- \\
\text { an } \\
\end{array}$ & $\begin{array}{c}100 \\
\%\end{array}$ & $\begin{array}{c}100 \\
\%\end{array}$ & $100 \%$ & $\begin{array}{c}100 \\
\%\end{array}$ & $\begin{array}{c}100 \\
\%\end{array}$ & $\begin{array}{c}100 \\
\%\end{array}$ & $\begin{array}{c}100 \\
\%\end{array}$ \\
\hline
\end{tabular}

Sumber : Penelitian (2021)

Tabel 14. Hasil Pengujian Back-End

\begin{tabular}{l|c|c|l|l|l}
\hline $\begin{array}{l}\text { Partisipa } \\
\mathrm{n}\end{array}$ & $\begin{array}{l}\text { Akses } \\
\text { Menu }\end{array}$ & $\begin{array}{c}\text { Akses } \\
\text { Data } \\
\text { Pemesana } \\
\mathrm{n}\end{array}$ & $\begin{array}{l}\text { Login } \\
\text { Administrato } \\
\mathrm{r}\end{array}$ & $\begin{array}{l}\text { Akses } \\
\text { Data } \\
\text { Transaks } \\
\mathrm{i}\end{array}$ & $\begin{array}{l}\text { Akses } \\
\text { Inbox }\end{array}$ \\
\hline 1 & $\checkmark$ & $\checkmark$ & $\checkmark$ & $\checkmark$ & $\checkmark$ \\
\hline 2 & $\checkmark$ & $\checkmark$ & $\checkmark$ & $\checkmark$ & $\checkmark$ \\
\hline Sukses & 2 & 2 & 2 & 2 & 2 \\
\hline $\begin{array}{c}\text { Nilai } \\
\text { Kesuksesa } \\
\text { n }\end{array}$ & $\begin{array}{c}100 \\
\text { Sumb }\end{array}$ & $100 \%$ & $100 \%$ & $100 \%$ & $\begin{array}{c}100 \\
\%\end{array}$ \\
\hline
\end{tabular}

Sumber : Penelitian (2021)

\section{KESIMPULAN}

Sistem Informasi Pemesanan Jasa Event Organizer Berbasis Web pada PT. Tekno Pasifik Indonesia ini menjadi salah satu solusi yang dapat digunakan untuk mempermudah perusahaan dalam melakukan promosi dan pengelolaan data pemesanan serta pembayaran, dan mempermudah pelanggan dalam melakukan pemesanan dan pembayaran. 
Hasil pengolahan data - data pada sistem informasi pemesanan jasa event organizer ini berupa laporan pemesanan dan pembayaran yang telah dilakukan.

Aplikasi yang dirancang ini berfungsi untuk membantu perusahaan dalam melakukan promosi, menyajikan laporan pemesanan dan pembayaran secara otomatis.

\section{REFERENSI}

Alkhalifi, Yuris, Windu Gata, Arfhan Prasetyo, and Imam Budiawan. 2020. "Analisis Sentimen Penghapusan Ujian Nasional Pada Twitter Menggunakan Support Vector Machine Dan Naïve Bayes Berbasis Particle Swarm Optimization.” Jurnal CoreIT 6(2).

Farlina, Yusti, Jamal Maulana Hudin, Ita Yulianti, and Marjan Maulana. 2019. "Rancang Bangun E-Commerce Berbantuan Sms Gateway Pada Audrey Batik Sukabumi." JURNAL SWABUMI $7(1)$.

Hakim, Zainul, Lilis Sakuroh, and Soni Awaludin. 2019. "Sistem Informasi Persediaan Barang Berbasis Web Pada CV Telaga Berkat." JURNAL SISFOTEK GLOBAL 09(01).

Juniansyah, Bayu Dwi, Erliyan Redy Susanto, and Agung Deni Wahyudi. 2020. "Pembuatan ECommerce Pemesanan Jasa Event Organizer Untuk Zero Seven Entertaiment.” 14(1):41-46.

Pratama, Muhammad Iqbal, and Muhammad Taufik Syastra. 2021. "Analisis Dan Perancangan Sistem Informasi Event Organizer Berbasis Web Di Antique Salon Dan Pelaminan." JURNAL COMASIE.

Puspita, Kartika, Yuris Alkhalifi, and Hasan Basri. 2021. "Rancang Bangun Sistem Informasi Penerimaan Peserta Didik Baru Berbasis Website Dengan Metode Spiral." Paradigma Jurnal Komputer Dan Informatika 23(1). doi: 10.31294/p.v23i1.10434.

Rudianto, Biktra, Yuni Eka Achyani, Indah Ariyati, and Universitas Nusa Mandiri. 2021. "Rancang Bangun Sistem Informasi Persediaan Obat Berbasis Web Menggunakan Model RAD." Jurnal Teknik Komputer AMIK BSI 7(2). doi: 10.31294/jtk.v4i2.

Septiani, Minda, Syarif Rahmanto, Verra Sofica, and Rahayu Ningsih. 2019. "Metode Waterfall Penjualan Mebel Properti Berbasis Web." Syarif Rahmanto 11(02).

Setiawan, Ridwan. 2019. "Perancangan Elektronik Marketplace Event Organizer." Algoritma 16(02).

Sofyan, Asep Abdul, Puput Puspitorini, and Muhammad Arif Yulianto. 2016. "Aplikasi Media Informasi Sekolah Berbasis SMS Gateway Dengan Metode SDLC (System Development Life Cycle)." JURNAL SISFOTEK GLOBAL 06(02).
Sukamto, Rosa Ariani, and Muhammad Shalahuddin. 2018. Rekayasa Perangkat Lunak. 